\title{
Careful risk assessment needed to evaluate transgenic fish
}

by Alison L. Van Eenennaam and Paul G. Olin

\section{The reproductive biology of fish} makes them particularly amenable to genetic manipulation. A genetically engineered or "transgenic" Atlantic salmon is currently undergoing federal regulatory review, and international research is being conducted on many other species. The innate ability of fish to escape confinement and potentially invade native ecosystems elevates the ecological concerns associated with their genetic modification. Escaped transgenic fish will not invariably result in deleterious effects on native populations, and careful risk assessment is required to determine the ecological risks unique to each transgene, species and receiving ecosystem combination. In response to public concerns about transgenic fish, California has developed stringent regulations for the importation, possession and raising of transgenic fish, and a California law prohibits their presence in waters of the $\mathrm{Pa}$ cific Ocean regulated by the state.

$\mathrm{T}$ he rationale for developing transgenic or genetically engineered animals for agricultural applications is essentially to increase their productivity and yield, improve their resistance to diseases and parasites, and enhance the nutritional and processing qualities of foods derived from these transgenic animals. Compared with mammals, fish offer important advantages for the production of transgenics because of the large number of eggs laid per female, the fact that fertilization and embryonic development takes place outside the mother (in most species), the lower probability of carrying human pathogens, and the fact that aquaculture is

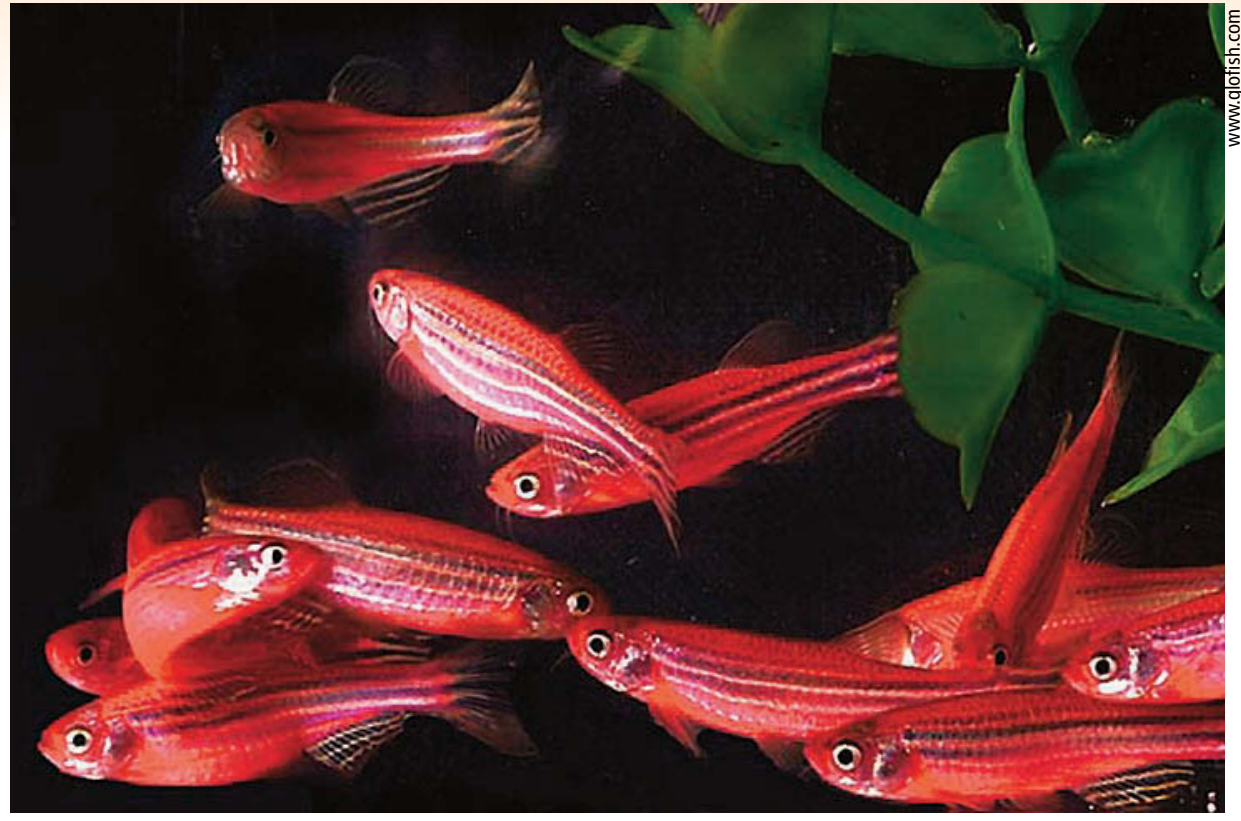

GloFish, a zebra danio that produce a red fluorescent protein, are the only transgenic fish that are commercially available in the United States. However, these aquarium fish are not available in California, which requires permits for the possession of genetically engineered fish.

a rapidly expanding market. The first transgenic fish were produced in 1984, and since that time more than 30 species have been genetically engineered worldwide (table 1).

The number of transgenic species is higher for fish than for all other vertebrate species combined. Transgenic fish have been developed for applications such as the production of human therapeutics, experimental models for biological research, environmental monitoring, ornamental fish and aquacultural production. Ironically, in addition to being the taxonomic group with the most transgenic species, aquatic organisms are also the most likely group to present environmental concerns if accidentally released into the environment. Unlike most other agricultural species, fish are both difficult to contain and highly mobile, and they can easily become feral and invade native ecosystems (NRC 2002).

\section{Transgenic fish defined}

Transgenic fish are those that carry and transmit one or more copies of a recombinant DNA sequence (i.e., a sequence produced in a laboratory using in vitro recombinant DNA techniques). They are defined by the technology that is used to create and transfer the DNA sequence, not the source species of the donor DNA. Therefore, fish engineered with recombinant DNA derived entirely from fish are considered transgenic.

The recombinant DNA sequence, or construct, is usually comprised of several different regions including a start signal or "promoter," the coding region for the target protein, and a stop signal or "terminator." The construct is usually introduced into the animal's genome through microinjection of the recombinant DNA fragment into fertilized eggs or early embryos.

Inducing transgenesis is a relatively inefficient process. Only about one out of every 100 eggs microinjected will stably incorporate the recombinant DNA sequence into its genome and subsequently transmit the transgene to its progeny. The growth hormone gene has been the most popular target gene for transgenesis, which is not surprising considering the potential cost savings in feed for such a product. At least 14 species of fish have been genetically modified for enhanced growth, and although they almost always grow faster than nontransgenic controls, they do not necessarily grow to a larger mature size.

There are, however, some startling examples of gigantism (Nam et al. 2001). 


\section{GLOSSARY}

Agonistic: Combative, striving to overcome.

A priori: Knowledge, judgments and principles that can be established independent of verification or testing.

\section{Genetic engineering: The} transfer of recombinant DNA sequences into the genome of a living organism.

Genome: The total DNA in a single cell, representing all of the genetic information of the organism. The normal human genome consists of 23 chromosomes from each parent.

Genotype: The entire genetic constitution of an organism, or the genetic composition at a specific gene locus or set of loci.

Meiosis: A special type of cell division by which eggs and sperm cells are made, involving reduction from a diploid (double) to a haploid (single) chromosome set.

Recombinant DNA: The laboratory manipulation of DNA in which DNA, or fragments of DNA from different sources, are cut and recombined using enzymes.

Transgene: A piece of DNA, typically a gene produced by recombinant DNA techniques, that is introduced into cells or organisms to modify the genome.

Transgenesis: The introduction of a recombinant DNA sequences into the genome of a living organism, leading to the transmission of the transgene to successive generations (see Genetic engineering).

Transgenic: An organism that has recombinant DNA in its genome. A transgenic organism is said to have been "genetically engineered."

TABLE 1. Examples of transgenes introduced into fish that cause significant phenotypic effects*

\begin{tabular}{|c|c|c|}
\hline Phenotype targeted & Species & Transgene \\
\hline Growth (> twofold) & $\begin{array}{c}\text { Atlantic salmon } \\
\text { Tilapia } \\
\text { Rainbow trout } \\
\text { Coho salmon } \\
\text { Chinook salmon } \\
\text { Rohu } \\
\text { Loach }\end{array}$ & Growth hormone \\
\hline Freeze tolerance & Atlantic salmon & Antifreeze protein \\
\hline Disease resistance & $\begin{array}{l}\text { Catfish } \\
\text { Carp } \\
\text { Medaka }\end{array}$ & $\begin{array}{l}\text { Cecropin } \\
\text { Lactoferrin } \\
\text { Cecropin }\end{array}$ \\
\hline Carbohydrate metabolism & $\begin{array}{l}\text { Rainbow trout } \\
\text { Rainbow trout }\end{array}$ & $\begin{array}{c}\text { Glucose transporter } \\
\text { Hexokinase }\end{array}$ \\
\hline Reproduction & Rainbow trout & Antisense GnRH \\
\hline Lipid metabolism & Zebrafish & D6-desaturase \\
\hline Phosphorus metabolism & Zebrafish & Phytase \\
\hline Vitamin C metabolism & Rainbow trout & $\begin{array}{c}\text { L-gulono-gamma-lactone } \\
\text { oxidase }\end{array}$ \\
\hline
\end{tabular}

Several studies have shown that growthenhanced transgenic fish have improved feed-conversion efficiency (Cook et al. 2000), resulting in economic and potential environmental benefits such as reduced feed waste and effluent from fish farms. Currently, no transgenic animal has been approved for food production in the United States, although that may change. A company called Aqua Bounty is currently awaiting regulatory review of its fish by the U.S. Food and Drug Administration (FDA).

\section{Growth-enhanced salmon proposed}

Atlantic salmon remains the most important farmed food fish in global trade. Salmon is a carnivorous fish, and aquaculturalists have been working to improve feed-conversion rates and efficiencies through selective breeding, and the inclusion of plant-based protein (soy, rapeseed oil and corn gluten) in feed formulations. As a consequence, feed input per fish has decreased to $44 \%$ of 1972 levels; likewise, current diets contain approximately half the content of fishmeal that they once did (Aerni 2004).

The first transgenic food animal to be submitted for regulatory approval in the United States was transgenic Atlantic salmon carrying a chinook salmon growth-hormone gene controlled by a cold-activated promoter from a third species, the ocean pout. The mature weight of these fish remains the same as for other farmed salmon, but their early growth rate increases by $400 \%$ to $600 \%$, with a concomitant $25 \%$ decrease in feed input and a shortened time to market (Du et al. 1992) (see photos, page 129). Assuming a positive regulatory approval decision and consumer acceptance, the enhanced growth rate and feed efficiency of these transgenic salmon could increase salmon aqua-

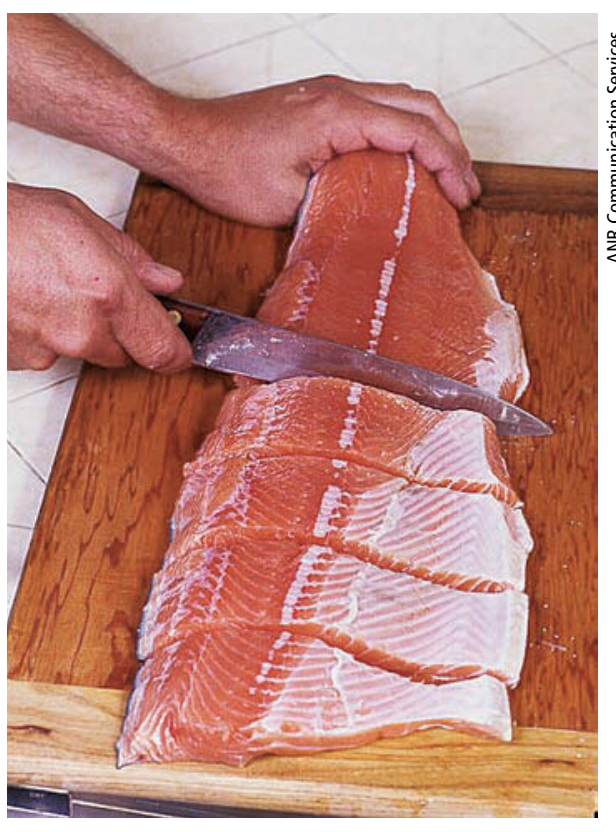

Transgenic fish are not currently produced for marketing purposes in the United States. Above, a consumer prepares salmon for cooking at home. 


\section{If transgenic fish are ill suited to an environment or are physically unable to survive outside of containment, then they may pose little risk to native ecosystems.}

cultural productivity significantly, and would likely necessitate that salmon aquaculturists adopt the technology to remain competitive (Aerni 2004).

Release or escape. The greatest science-based concerns associated with transgenic fish are those related to their inadvertent release or escape. Concerns range from interbreeding with native fish populations (Muir and Howard 2002) to ecosystem effects resulting from heightened competition for food and prey species. In principle, there is no difference between the types of concerns associated with the escape of genetically engineered fish and those related to the escape of fish that differ from native populations in some other way, such as a captively bred population (Lynch and O'Hely 2001). Ecological risk assessment requires an evaluation of the fitness of the transgenic fish relative to nontransgenic fish in the receiving population, to determine the probability

\section{Risk factors of transgenic fish}

that the transgene will spread into the native population. Fitness is defined as the genetic contribution by an individual's descendants to future generations of a population. It can be reduced to six net fitness components: juvenile viability, adult viability, age at sexual maturity, female fecundity (number of eggs), male fertility and mating success (Muir and Howard 2001).

The importance of accurately estimating each of the components of net fitness is demonstrated by the hazard exemplified by the "Trojan gene hypothesis." In this specific situation, the transgene confers enhanced mating success, but individuals possessing the transgene produce offspring with reduced juvenile viability. Depending upon the relative magnitude of the effects, an outcome associated with this particular set of circumstances can be the demographic destabilization and ultimate extinction of the native population (Muir and Howard 1999; Hedrick 2001). It is therefore im-

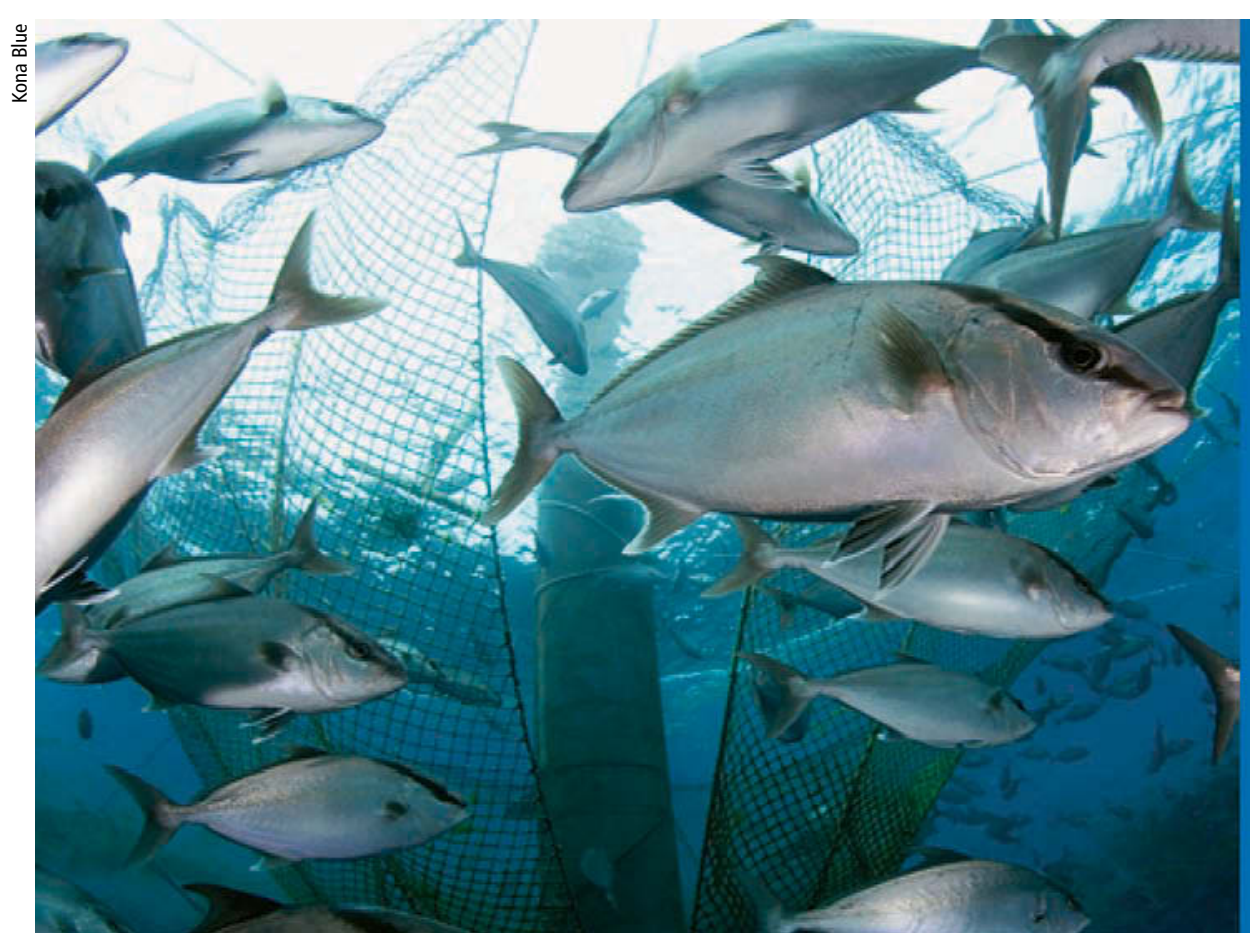

The containment of transgenic fish will be a critical component of any commercialization strategy, to prevent interbreeding with wild, native fish. Above, a large-scale fish farming cage off Hawaii. portant to evaluate each species and transgene combination on a case-bycase basis to estimate the components of net fitness relative to nontransgenic fish in the receiving population (Muir and Howard 2004).

Environmental factors. In addition to interbreeding, it is also important to consider the potential impact that environmental factors may have on the survival of transgenic and nontransgenic populations (i.e., genotype-byenvironment interactions). A recent study of growth-enhanced transgenic and nontransgenic salmon found that transgenic salmon did not affect the growth of nontransgenic cohorts when food availability was high (daily feed ration equivalent to $7.5 \%$ of total fish biomass). However, the survival of both transgenic and nontransgenic cohorts was deleteriously affected when feed resources were limited to $0.75 \%$ of total fish biomass. The fast-growing transgenic salmon were found to dominate feed acquisition and exhibit strong agonistic and cannibalistic behavior toward their cohorts when there were inadequate feed resources (Devlin et al. 2004). Hunger and increased growth rates have been previously associated with agonistic behavior in nontransgenic salmonids, although in this experiment, unmodified populations receiving the reduced feed ration did not display such behavior.

The presence of transgenic fish will not a priori result in catastrophic results for native populations. If transgenic fish are ill suited to an environment or are physically unable to survive outside of containment, then they may pose little risk to native ecosystems. It is important to realize that neither the risks nor the benefits of transgenic fish are certain or universal. Both may vary according to a number of factors including the introduced gene, host species, containment strategy, species mobility, ability to become feral, relative fitness of the transgenic fish, receiving ecosystem, genotype-by-environmental interactions, and the stability of the receiving community. Regulators need to apply a scientifically sound, risk-based framework to assess the ecological risks involved with each transgene, species and 
receiving ecosystem combination on a case-by-case basis.

\section{Containment of transgenic fish}

The commercialization of transgenic fish likely will be dependent upon the development of effective containment strategies. If transgenic fish are adequately contained, then they will pose little risk to native populations. The National Research Council (NRC 2004) recommended the simultaneous use of multiple containment strategies for transgenic fish, an approach that is consistent with the redundant fail-safe mechanisms used in other industries (e.g., the aircraft industry) where critical control must be maintained at all times.

Physical containment is an obvious first line of defense to prevent the escape of transgenic fish. Examples of such measures may include building facilities on land or removed from native populations, or ensuring that water chemistry (temperature, $\mathrm{pH}$, salinity, concentrations of certain chemicals) is lethal to one or more life stages of the transgenic fish, such as treating effluent water to prevent the release of viable gametes or fry. Biological containment or bioconfinement approaches such as sterilization also are being developed (Fu et al. 2005; Maclean et al. 2002; Slanchev et al. 2005; Uzbekova et al. 2000).

The sterilization of transgenic fish would go a long way toward reducing the interbreeding risks associated with the escape of transgenic fish. Aqua Bounty plans to biologically contain its transgenic salmon by selling only triploid, all-female transgenic fish. Triploid fish, carrying three sets of chromosomes rather than the usual two, can be obtained by heat or pressure "shocking" the egg soon after fertilization to prevent the extrusion of the second polar body. Triploid fish are unable to produce viable eggs due to the fact that the third chromosome set interferes with the process of meiosis. Unfortunately, triploidy induction methods are not sufficiently effective to consistently ensure $100 \%$ sterility. The individual identification of fertile diploid larvae within batches of triploid larvae using particle analysis or flow cytometry of blood cells is an expensive proposi-

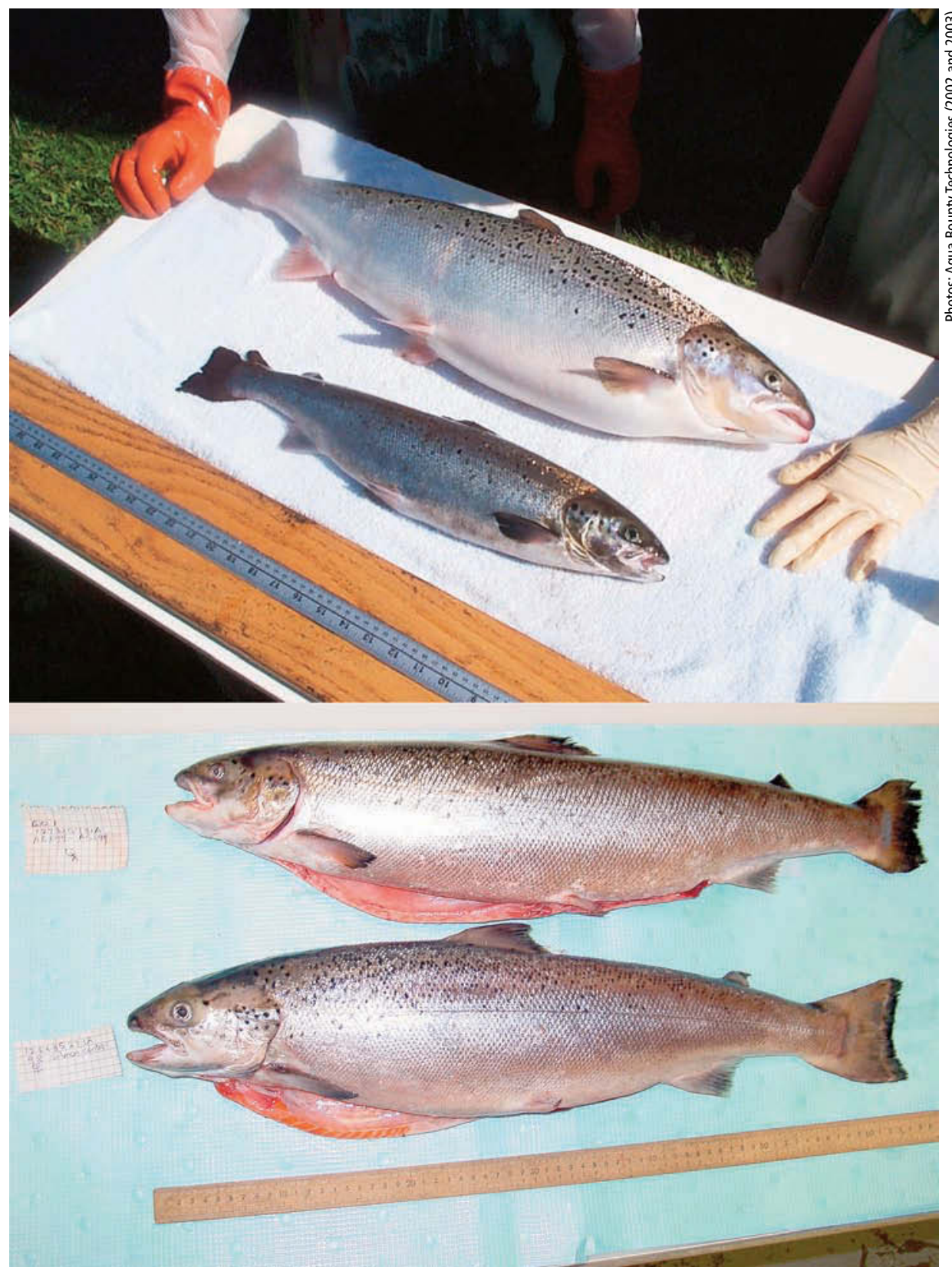

Aqua Bounty has applied for federal approval to commercially produce a growth-enhanced, transgenic Atlantic salmon (Salmo salar). Top, at 18 months, the transgenic fish is clearly much larger than the same-age normal fish. Above, overall growth of the same generation of fish has evened out by 36 months.

tion. Aqua Bounty plans to verify the sterility of every batch of transgenic salmon eggs using flow cytometry before they leave the hatchery.

Researchers are working on other genetic containment approaches including transgenic methods for the induction of sterility. A similar approach to genetically engineer sterility into transgenic plant seeds, dubbed the "terminator" technology, engendered a hostile response from certain environmental and farmer groups. In that case, concerns centered more on the effect that the technology would have on the farmer's right to save and replant seeds from their harvest, rather than on its potential to circumvent transgene escape. Whether the additional costs associated with containment will ultimately outweigh production savings or other benefits conferred by transgenes remains to be seen.

\section{Global and U.S. regulations}

While many countries have developed regulations for transgenic plant 
varieties, few have similar regulations for transgenic animals. Government agencies in Cuba and China are currently reviewing proposals for the commercialization of genetically modified fish (Pew Initiative on Food and Biotechnology 2003). There are currently no international standards regarding the confinement of transgenic fish to prevent their potential release or escape into the environment.

In the United States, the use of transgenic fish is federally regulated under the Food, Drug and Cosmetics Act, with the FDA's Center for Veterinary Medicine (CVM) asserting primary jurisdiction over transgenic animals. Transgenic animals for production fall under CVM regulation as new animal drugs. Investigational applications are filed requesting approval for genebased modifications, and following the provision of adequate safety data, the sponsor may request approval for these animals to be used for food or processing into animal feed components.

To date, no transgenic animals have been approved for use as human food, although the Aqua Bounty transgenic Atlantic salmon has been under regulatory review for more than 5 years. A limited number of transgenic animals have been approved for rendering into animal feed components (FDA 2006).

To coordinate multiple-agency federal oversight of transgenic organisms, the "Coordinated Framework" was adopted in 1986 to clarify the regulatory authority of the FDA, the U.S. Environmental Protection Agency (EPA) and the U.S. Department of Agriculture (USDA). These three agencies share jurisdiction over transgenic organisms through the Food, Drug, and Cosmetics Act (FFDCA), the Federal Insecticide, Fungicide, and Rodenticide and the Toxic Substances Control acts (EPA), and the Plant Pest Protection, the Plant Quarantine and the Virus, Serum, and Toxin acts (USDA). The Office of Science and Technology Policy published a package of regulatory case studies in 2001 in which the FDA indicated that it "intends to publish draft guidance on how the new animal drug provisions of the FFDCA pertain to transgenic animals,

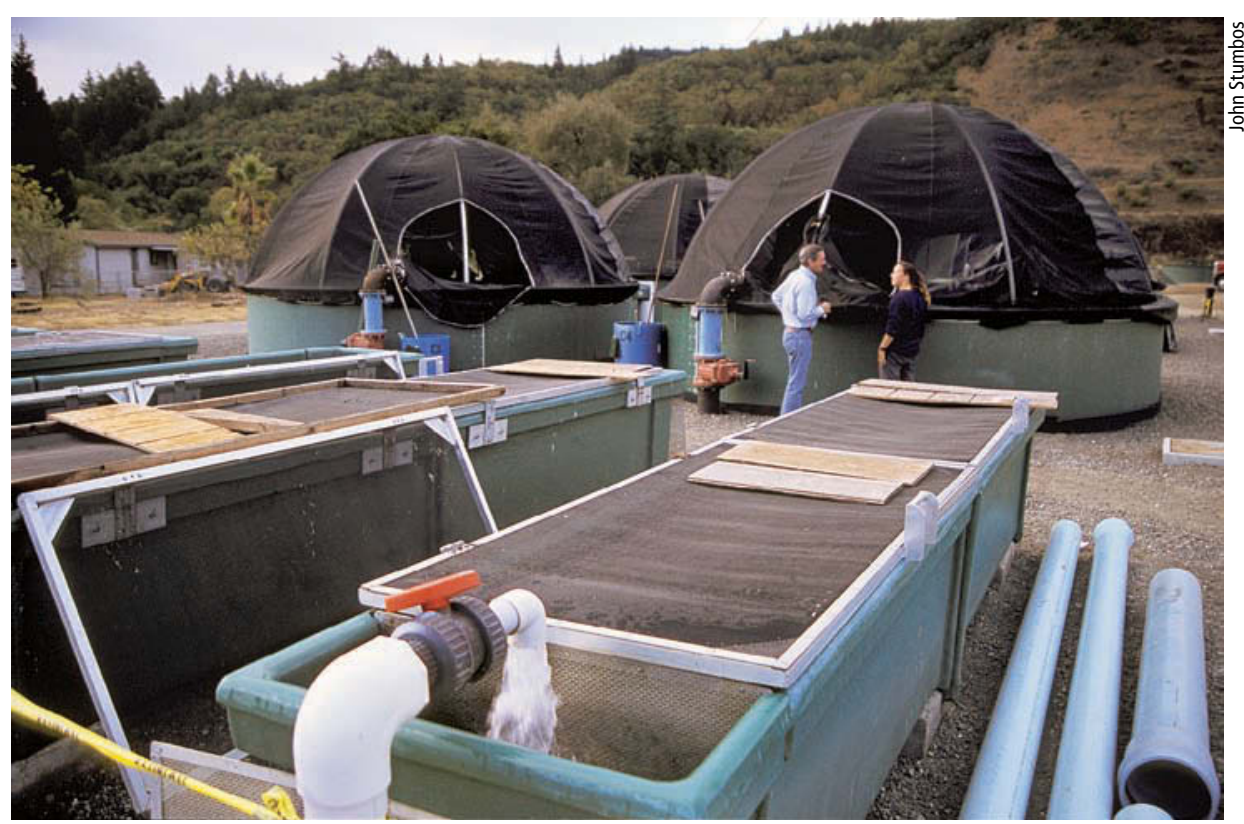

Above, endangered native (nontransgenic) coho salmon are reared for a restoration effort at the Don Clausen Warm Springs Hatchery near the Russian River in Northern California. California regulations prohibit the importation or rearing of transgenic fish without a permit, in part due to concerns about risks to native fish populations.

and on procedures by which companies developing transgenic animals can comply with those provisions." However, the government has issued no further guidance on the scope or implementation of such a policy.

In addition to ensuring food safety, the FDA also evaluates environmental risks posed by transgenic animals as directed by the National Environmental Policy Act (NEPA). Under NEPA, federal agencies are obligated to cooperate with other involved federal agencies, and in the case of the Aqua Bounty transgenic salmon, this cooperation includes working with the U.S. Fish and Wildlife Service and the National Marine Fisheries Service in the development of a scientifically based environmental risk assessment.

\section{California weighs in}

California was the first state to consider legislation to amend the Fish and Game Code to make it unlawful to import, transport, possess or release any live transgenic fish, or their roe, except under a permit. The bill, SB 1525, was introduced in 2002 and was supported by the Institute for Fisheries Resources, the Natural Resources Defense Council, The Ocean Conservancy, and a number of other groups, based on concerns that transgenic fish escaping into the wild might adversely affect the environment.
SB 1525 did not pass and subsequently, its proponents sought another avenue to achieve their goals and petitioned the California Fish and Game Commission to prohibit the introduction of genetically altered fish into the state.

The Commission denied this petition, but then instructed the California Department of Fish and Game (DFG) to develop rules and regulations governing the use of transgenic fish in the state. A working group formed by DFG in cooperation with industry and environmental stakeholders - including the Natural Resources Defense Council, The Ocean Conservancy, UC and the California Aquaculture Association - worked collaboratively to establish these rules (California Code of Regulations 2003).

A permit is required under these rules to import, transport, possess, rear or conduct research on genetically modified fish in California. They must be kept in closed-water systems or ones that do not allow the inadvertent release of live fish, and access to facilities containing transgenic fish must be restricted. The Fish and Game Commission unanimously accepted these regulations in 2003, effectively adding transgenic aquatic animals to the state's list of restricted species. The regulations also require public comment, and the Commission must hold a 
There are currently no international standards regarding the confinement of transgenic fish to prevent their
potential release or escape into the environment.

public hearing for each permit application to ensure that any permit granted is in the public's best interest.

Additional California legislation related to transgenic fish was introduced in the 2003 legislative session as SB 245. This bill contains in part the following language: "In the waters of the Pacific Ocean that are regulated by this state, it is unlawful to spawn, incubate, or cultivate any species of finfish belonging to the family Salmonidae, transgenic fish species, or any exotic species of finfish." The bill exempts native California stocks that are propagated and cultured for release into ocean waters for the purpose of recovery, restoration or enhancement of California's native salmon and steelhead trout populations. This legislation passed both the California Assembly (50 to 26) and Senate (22 to 14), effectively precluding transgenic fish from coastal net-pen aquaculture up to 3 miles off California's shore.

\section{What about GloFish?}

In 2003, a transgenic zebra danio that produces a red fluorescent protein became commercially available in most U.S. pet shops. The zebra danio is a small aquarium species that has never survived outside captivity in the United States, despite repeated intentional and accidental releases. Federally, the FDA decided not to formally regulate GloFish. The rationale for this decision was explained in the following FDA statement: "Because tropical aquarium fish are not used for food purposes, they pose no threat to the food supply. There is no evidence that these genetically engineered zebra danio fish pose any more threat to the environment than their unmodified counterparts, which have long been widely sold in the United States. In the absence of a clear risk to the public health, the FDA finds no reason to regulate these particular fish."

This lack of formal regulation was seen by some as a "dangerous precedent" for the regulation of transgenic animals. Despite the FDA's decision not to regulate the commercial sale of GloFish, they are not currently available from pet stores in California as a result of the DFG regulations requiring a permit to import, transport, possess or rear genetically modified fish in onshore water systems.

\section{Consumer acceptance will decide}

In the near term, it is the marketplace more than the science that will decide the fate of new technologies and acceptability of certain risks. Food retailers and even farmers may be unwilling to stock the transgenic fish and risk having their market become the target of an organized anti-biotech campaign (Aerni 2004). Such a scenario occurred in Europe, where activist campaigns targeted retailers stocking labeled genetically engineered food products. Attempts to differentiate brands resulted in the removal of these products from supermarket shelves altogether (Kalaitzandonakes and Bijman 2003).

Despite strong public support for medical applications of genetic engineering, there is less public support for agricultural biotechnology. Market response and consumer behavior may differ markedly between affluent Western countries and those found in developing countries. Even if the FDA approves transgenic fish in the United States, it will likely be activist, food retailer and consumer responses in the marketplace that will ultimately decide whether transgenic food fish will sink or swim.

A.L. Van Eenennaam is Animal Genomics and Biotechnology Cooperative Extension Specialist, UC Davis; and P.G. Olin is Director and Marine Advisor, UC Cooperative Extension Sea Grant.

\section{References}

Aerni P. 2004. Risk, regulation and innovation: The case of aquaculture and transgenic fish. Aquat Sci 66(3):327-41.

California Code of Regulations. 2003. Permits for Restricted Species. Subsection (a)(9), Section 671. Title 14. www.fgc.ca.gov/2003/671_1regs.pdf.
Cook JT, McNiven MA, Richardson GF, et al. 2000. Growth rate, body composition and feed digestibility/conversion of growth-enhanced transgenic Atlantic salmon (Salmo salar). Aquaculture 188(1-2):15-32.

Devlin RH, D'Andrade M, Uh M, et al. 2004. Population effects of growth hormone transgenic coho salmon depend on food availability and genotype by environment interactions. Proc Natl Acad Sci USA 101(25):9303-8.

Devlin RH, Sundstrom LF, Muir WM. 2006. Interface of biotechnology and ecology for environmental risk assessments of transgenic fish. Trends Biotechnol 24 (2):89-97.

Du SJ, Gong ZY, Fletcher GL, et al. 1992. Growth enhancement in transgenic Atlantic salmon by the use of an all fish chimeric growth-hormone gene construct. Bio-Technol 10(2):176-81.

[FDA] US Food and Drug Administration. Questions and answers about transgenic fish. Center for Veterinary Medicine. www.fda.gov/cvm/transgen.htm (accessed 5/31/06).

Fu C, Hu W, Wang Y, et al. 2005. Developments in transgenic fish in the People's Republic of China. Revue Scientifique et Technique-Office International des Epizooties 24(1):299-307.

Hedrick PW. 2001. Invasion of transgenes from salmon or other genetically modified organisms into natural populations. Can J Fish Aquat Sci 58(5):841-4.

Kalaitzandonakes N, Bijman J. 2003. Who is driving biotechnology acceptance? Nat Biotechnol 21(4):366-9.

Lynch M, O'Hely M. 2001. Captive breeding and the genetic fitness of natural populations. Conserv Genet 2:363-78.

Maclean N, Rahman MA, Sohm F, et al. 2002. Transgenic tilapia and the tilapia genome. Gene 295(2):265-77.

Muir WM, Howard RD. 1999. Possible ecological risks of transgenic organism release when transgenes affect mating success: Sexual selection and the Trojan gene hypothesis. Proc Natl Acad Sci USA 96(24):13853-6.

Muir WM, Howard RD. 2001. Fitness components and ecological risk of transgenic release: A model using Japanese medaka (Oryzias latipes). Am Nat 158(1):1-16.

Muir WM, Howard RD. 2002. Assessment of possible ecological risks and hazards of transgenic fish with implications for other sexually reproducing organisms. Transgenic Res 11(2):101-14.

Muir WM, Howard RD. 2004. Characterization of environmental risk of genetically engineered (GE) organisms and their potential to control exotic invasive species. Aquat Sci 66(4):414-20.

Nam YK, Noh JK, Cho YS, et al. 2001. Dramatically accelerated growth and extraordinary gigantism of transgenic mud loach Misgurnus mizolepis. Transgenic Res 10(4):353-62.

[NRC] National Research Council. 2002. Animal Biotechnology: Science-Based Concerns. Washington, DC Nat Acad Pr. 181 p.

NRC. 2004. Biological Confinement of Genetically Engineered Organisms. Washington, DC: Nat Acad Pr. $255 \mathrm{p}$.

Pew Initiative on Food and Biotechnology. 2003. Future Fish: Issues in Science and Regulation of Transgenic Fish. Washington, DC. 72 p. http://pewagbiotech. org/research/fish.

Slanchev K, Stebler J, Cueva-Mendez G, et al. 2005 Development without germ cells: The role of the germ line in zebrafish sex differentiation. Proc Nat Acad Sci USA 102(11):4074-9.

Uzbekova S, Chyb J, Ferriere F, et al. 2000. Transgenic rainbow trout expressed $s \mathrm{GnRH}$-antisense RNA under the control of sGnRH promoter of Atlantic salmon. J Mol Endocrinol 25(3):337-50. 